a medulla enlarged by multiple cysts varying in diameter from $50 \mu$ to $2 \mathrm{~cm}^{1-8}$

The pathogenesis of cystic disease of the renal medulla is as obscure as that of polycystic kidneys. ${ }^{6}$ It is not known whether the inherited defect is an anatomical malformation or whether the malformation results from an inborn error of metabolism. ${ }^{3}$ It is interesting to note that cystic renal disease can be produced in rats with diphenylamine, ${ }^{11}$ salutary to recall that cysts have often been attributed to bacterial infection of the kidneys, ${ }^{6}$ and also relevant that kidneys transplanted into patients with medullary cystic disease have not so far been noted to develop cysts. ${ }^{6}$

The finding of associated congenital anomalies often provides the clue to the diagnosis of a familial renal disease. Thus malformations of the ear, deafness, multiple structural abnormalities, Marfan's syndrome, and visual defects including retinitis pigmentosa, tape to retinal degeneration, and congenital cataracts are all recognized as pointers to a congenital basis for renal disease. ${ }^{12-13} \mathrm{Red}$ and blonde hair must now be added to this list. E. J. Rayfield and F. D. McDonald ${ }^{14}$ have recently reported eight patients from four families in whom medullary cystic disease was associated with red hair in six and blonde hair in two. They have drawn attention to an incidental observation made by $G$. W. Thorn and his co-workers when describing hormonal studies in four patients with gross salt-losing nephritis-three of these four patients had red hair and the fourth was blonde. ${ }^{15}$ In nephrology, where biochemical studies figure so prominently, the clinical observation of an association between red or blonde hair and chronic renal disease with salt wasting should not pass unnoticed. It is also possible that this further associated congenital anomaly will enable renal physicians to broaden the spectrum of renal diseases in which a congenital factor is recognized.

\footnotetext{
1 Strauss, M. B., and Sommers, S. C., New England fournal of Medicine, $1967,277,863$.

Mongeau, J. G., and Worthen, H. G., American fournal of Medicine,

1967, 43, 345.
Herdman, R. C., Good, R. A., and Vernier, R. L., American fournal of Medicine, 1967, 43, 335 .

Axelsson, U., and Odlund, B., Acta Medica Scandinavica, 1968, 183, 275.

5 Smith, C. H., and Graham, J. B., American fournal of Diseases of Children, $1945,69,369$.

- Strauss, M. B., in Diseases of the Kidney, ed. M. B. Strauss and L. G. Welt, 2, p. 1259. Boston, Little Brown, 1971.

${ }^{7}$ Fanconi, G., et al., Helvetica Paediatrica Acta, 1951, 6, 1.

8 Goldman, S. H., Walker, S. R., Merigan, T. C., Gardner, K. D., and Bull, J. M. C., New England fournal of Medicine, 1966, 274, 984.

- Giselson, N., et al., American fournal of Medicine, 1970, 48, 174.

10 Spicer, R. D., Ogg, C. S., Saxton, H. M., and Cameron, J. S., British

11 Kime, S. W., et al., fournal of Laboratory and Clinical Medicine, 1962, 60,

12 Fairley, K. F., Leighton, P. W., and Kincaid-Smith, P., British Medical

13 Meirnal, 1963, 1, 1060. 14 Rayfield, E. J., and McDonald, F. D., Archives of Internal Medicine, 1972, 130, 72.

15 Thorn, G. W., Goldfien, A., Suiter, T. B., and Dammin, G., Medical Clinics of North America, 1960, 44, 1139.
}

\section{Deaths in England and Wales}

The standardized death rate in England and Wales declined slowly over the years to a level in 1971 that was $86 \%$ of the rate for $1950-2:^{\circ}$ Its greatest reduction was from about the end of the first world war to the end of the second, when it was halved. Now further gains seem likely to be small until a therapeutic breakthrough comparable to that of the sul- phonamide-penicillin era is attained. The infant mortality rate too has been stagnant for some years, being an unchanging 18 per thousand live births for each of the five years 1967-71.1

The rate of death from acute myocardial infarction continues to increase. It remains the outstanding cause of death, and rose by $17 \%$ during the 10 years $1962-71$ to cause 2,043 deaths per million population in the latter year. As a cause of death it is about $50 \%$ commoner among men than women. By contrast deaths from cerebrovascular disease are nearly $50 \%$ commoner among women; they have remained at much the same level for several years. Hypertensive disease has greatly declined as a cause of death, possibly as a result of more effective drug treatment. From 1962 to 1971 it fell by $41 \%$ to reach a level of 191 per million population, and it too affects women considerably more than men. Of the commoner diseases that are increasing as causes of death the most notable is diabetes mellitus. Between 1962 and 1971 deaths from it among men rose by $25 \%$ and among women by $13 \%$.

1 Registrar General's Statistical Review of England and Wales for the Year 1971, Part 1, Tables, Medical. London, H.M.S.O., 1973.

\section{Hospital Strikes and Infection}

Doctors are responsible not only for the medical care of their patients; they are responsible also for the hospital environment in which they place them. The dangers in the present situation are threefold. Firstly, the lack of daily thorough ward cleaning will lead to a build up of ward infection which will take weeks to overcome. The antibiotic-resistant staphylococcus has been difficult enough to contain, especially in surgical wards, and it must be recognized that there are now added risks which will need added precautions. Secondly, there is the problem of vast amounts of soiled bed linen, which must sometimes contain pathogens. This is a danger not only to patients but also to the ancillary workers themselves. There are plenty of examples in mental hospitals and children's nurseries of the epidemic propensities of soiled linen. In fact, epidemic spread under such circumstances is held in check only by the high hygienic standards which are the rule in the hospital service. Hence the decision to discharge as many patients as possible was justified if only to assist in the prevention of infection. The prime factor in the control of hospital infection is scrupulous attention to cleanliness.

Thirdly, but equally important, is the danger of foodborne infections. With inadequate catering staff and inexperienced volunteers the risk of food and drink infections is greatly increased. It has been shown repeatedly, not least in the weekly reports in the B.M.F. from the Public Health Laboratory Service, that once hygienic standards are relaxed in any communal living establishment it is only a matter of time until an outbreak of gastrointestinal infection occurs. Surely nobody wants this to happen to sick people, and least of all the elderly, the physically and mentally disabled, and the incontinent, who suffer so much and have no spokesman. Infection is a real and serious menace under the present conditions, and it is courting disaster to allow them to continue. 